
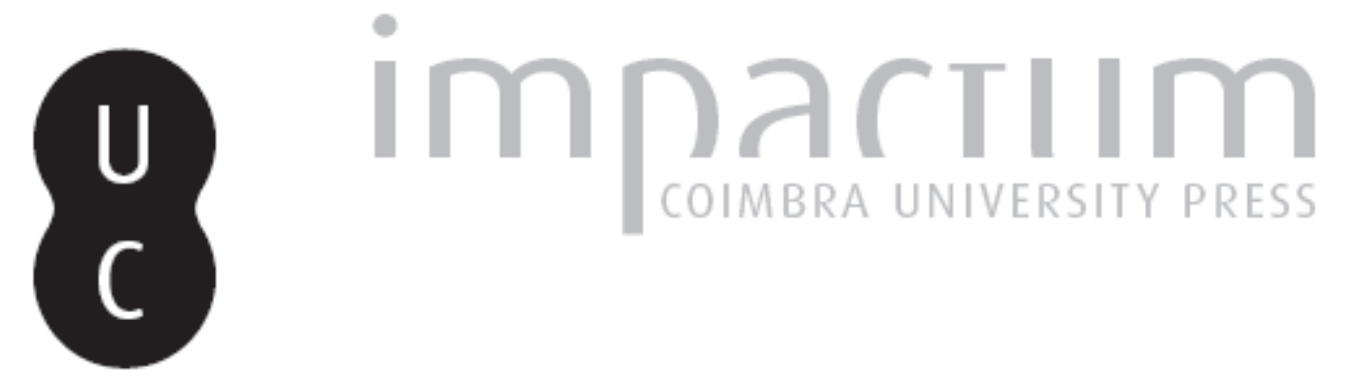

\title{
O sortilégio do olhar: Helena na pintura de Gustave Moreau
}

\section{Autor(es): $\quad$ Ferreira, Luísa de Nazaré}

Publicado por: Centro de História da Universidade de Lisboa

URL persistente:

URI:http://hdl.handle.net/10316.2/23751

DOI:

DOI:http://dx.doi.org/10.14195/0871-9527_20_22

Accessed : $\quad$ 26-Apr-2023 15:54:16

A navegação consulta e descarregamento dos títulos inseridos nas Bibliotecas Digitais UC Digitalis, UC Pombalina e UC Impactum, pressupõem a aceitação plena e sem reservas dos Termos e Condições de Uso destas Bibliotecas Digitais, disponíveis em https://digitalis.uc.pt/pt-pt/termos.

Conforme exposto nos referidos Termos e Condições de Uso, o descarregamento de títulos de acesso restrito requer uma licença válida de autorização devendo o utilizador aceder ao(s) documento(s) a partir de um endereço de IP da instituição detentora da supramencionada licença.

Ao utilizador é apenas permitido o descarregamento para uso pessoal, pelo que o emprego do(s) título(s) descarregado(s) para outro fim, designadamente comercial, carece de autorização do respetivo autor ou editor da obra.

Na medida em que todas as obras da UC Digitalis se encontram protegidas pelo Código do Direito de Autor e Direitos Conexos e demais legislação aplicável, toda a cópia, parcial ou total, deste documento, nos casos em que é legalmente admitida, deverá conter ou fazer-se acompanhar por este aviso.

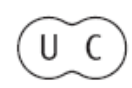




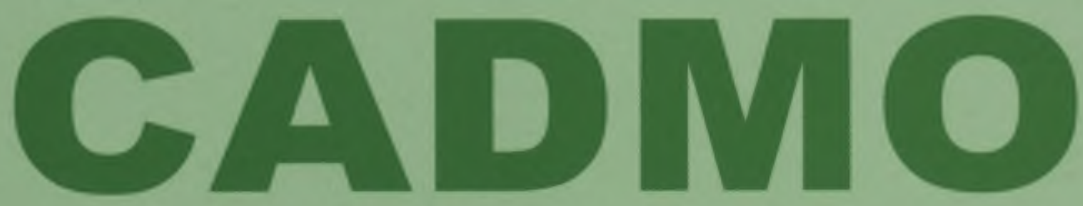

Revista de História Antiga

\author{
Centro de História \\ da Universidade de Lisboa
}

\title{
20
}

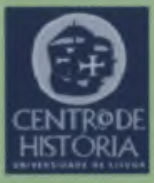

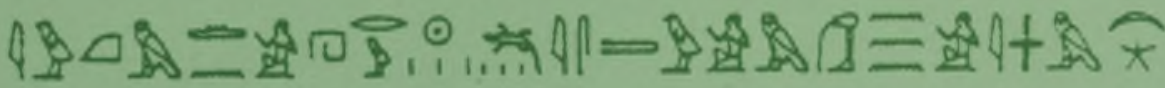

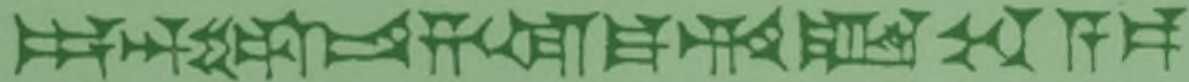

MHNIN AEI $\Delta$ E $\Theta E A ~ \Pi H \Lambda H I A \triangle E \Omega$ 


\title{
O SORTILÉGIO DO OLHAR. HELENA NA PINTURA DE GUSTAVE MOREAU
}

\author{
LUÍSA DE NAZARÉ FERREIRA \\ Universidade de Coimbra \\ luisanazare@ hotmail.com
}

\section{Resumo}

No tratamento do mito de Helena, os pintores de vasos gregos elegeram como temas principais o nascimento $a b$ ovo, o rapto por Teseu e Páris e o encontro violento com Menelau em Tróia. Gustave Moreau (Paris, 18261898), porém, preferiu a imagem da rainha de Esparta sobre as muralhas de Tróia, apresentada no canto III da llíada. Na parte final da vida do pintor, sob a influência do Segundo Fausto de Goethe, o poder sedutor da beleza feminina adquire novo colorido, mas a apoteose de Helena é também um regresso às antigas tradições gregas que a consideravam uma deusa. $\left({ }^{*}\right)$

Palavras-chave: Helena; mito; arte; pintura simbolista; Gustave Moreau.

\begin{abstract}
Helen's birth $a b$ ovo, her abduction by Theseus and Paris, the violent meeting with Menelaus in Troy were the main subjects of Greek vase painting. However, Gustave Moreau (Paris, 1826-1898) was deeply impressed by Helen's description coming towards the tower of Troy in Iliad (Book III). In the last part of his life, the seductive power of female beauty achieves new colours under the influence of Goethe's Faust II. But the apotheosis of Helen is also a return to the ancient Greek traditions, which considered her a goddess.
\end{abstract}

Keywords: Helen; Myth; Art; Symbolist Painting; Gustave Moreau. 
A complexa lenda de Helena desde muito cedo constituiu uma fonte de inspiração para os artistas gregos, especialmente para os pintores de vasos. O extenso catálogo iconográfico, reunido e estudado em pormenor por Lilly Ghali Kahil, pode hoje ser apreciado nas páginas do IV.. volume do Lexicon Iconographicum Mythologiae Classicae (LIMC), publicado em 1988. Um exame breve mostra que das muitas peripécias vividas pela princesa de Esparta, que veio ao mundo em circunstâncias singulares, a cerâmica grega deu primazia ao seu rapto, primeiro cometido por Teseu e depois por Páris, à sua paixão pelo príncipe troiano, bem como ao reencontro violento com o marido ultrajado, Menelau. Não admira, portanto, que a mesma investigadora, membro da École Française d'Athènes, tenha estudado precisamente esta matéria na dissertação de doutoramento Les enlèvements et le retour d'Hélène dans les textes et les documents figurés, apresentada à Faculdade de Letras da Universidade de Paris em 1955.

A divulgação da lenda do nascimento de Helena $a b$ ovo parece dever-se aos Cantos Cíprios, embora nesta versão a mãe seja Némesis, a quem Zeus se une sob a forma de cisne. O ovo, porém, é confiado a Leda que cria Helena como sua filha. O prólogo da tragédia homónima de Eurípides, proferido pela própria princesa de Esparta, alude à tradição mais célebre, a que indicava como progenitores Zeus e Leda (vv. 17-20), embora nada diga sobre o nascimento ab ovo. O drama euripidiano foi apresentado em 412 a. C. e nessa época o mito era já muito conhecido(1). Todavia, embora antigo, não aparece representado nas pinturas de vasos antes da segunda metade do século $\mathrm{V}$ a. C. Chamamos apenas a atenção para duas das peças mais interessantes:

- Um krater-de-sino apúlio do primeiro quartel do século IV a. C. retrata uma encenação cómica do tema. À esquerda, uma figura feminina assustada, provavelmente Leda, espreita através da porta entreaberta o que poderia ter sido um parto desastroso: uma personagem masculina prepara-se para rachar, com um enorme machado, o ovo colocado dentro de um cesto. A bela Helena, porém, já está a nascer, de braço direito erguido a indicar que tal violência é desnecessária. Uma outra figura masculina, à direita, acompanha o seu gesto. Helena nasce já formada, à semelhança das deusas Atena e Afrodite. Não tem as formas de um bebé, mas de uma jovem de corpo bem feito. Sedutora desde o primeiro momento de vida, o pintor não se esqueceu de the compor o cabelo(2). 
- Um krater-de-sino campaniense da segunda metade do século IV a. C. ilustra o tratamento sério do mesmo tema: Leda e Tíndaro aguardam, com deleite, o nascimento de Helena, que sai triunfante, de braços abertos, de um ovo pousado sobre um altar ${ }^{(3)}$.

O rapto de Helena por Teseu, que a epopeia homérica apenas subentende e está pouco atestado nas fontes literárias ${ }^{(4)}$, conheceu diversos tratamentos iconográficos desde muito cedo. Numa hydria de figuras negras do fim do século VI a. C., atribuída ao Grupo de Leagro, Teseu toma a direcção de Pirítoo, o companheiro que, à esquerda, sobe para o carro, enquanto Helena estende os braços para as figuras femininas que acorrem do lado direito(5), um gesto convencional para sugerir que o rapto ocorre contra a sua vontade.

A inscrição MENE $\Lambda E O \Sigma$ num lécito atribuído ao Pintor de Brigos, do início do século $V$ a. C., permite identificar o jovem guerreiro, retratado sem barba, e a sua tímida noiva. A decoração evoca as bodas de Menelau e Helena(6).

Mais frequente é a representação do reencontro violento no fim da guerra de Tróia. Numa peça de figuras vermelhas pintada por Oltos por volta do fim do século VI a. C., Helena segue, obediente, um Menelau que a segura pelo punho e para ela dirige a espada ameaçadora. É a única representação deste género em que as personagens são nomeadas ${ }^{(7)}$. Uma hydria de figuras vermelhas da primeira metade do século $V$ a. C., atribuída ao Pintor de Sirisco, atesta uma variante deste tema: Menelau avança para a direita com a espada na mão em direcção a Helena, que tenta fugir e ergue os braços, em gesto de súplica, tal como a outra figura feminina, que tem sido identificada com Afrodite ${ }^{(8)}$.

Convém recordar que a identificação das personagens retratadas nestas cenas não está a salvo de dificuldades nem de erros, como têm mostrado alguns estudiosos, designadamente Meret Mangold. O tema do rapto, como é sabido, é muito comum quer na mitologia grega e romana quer na iconografia. Não obstante estes problemas de interpretação, pretendíamos somente destacar os temas que mais tarde serão também privilegiados na cultura europeia da nossa era, designadamente na pintura ${ }^{(9)}$. Não é muito comum os artistas retratarem a figura de Helena isolada, como numa obra do simbolismo alemão, Helen, de Franz von Stuck, realizada em 1924. Do mesmo modo, na cerâmica antiga raramente a cena recriada surge desprovida de acção ou movimento, pois os artistas gregos ilustram, em geral, uma história ou um momento particular do mito. Ao chamarmos a atenção 
para este aspecto, entramos no tema central deste trabalho: a presença de Helena na obra de Gustave Moreau.

Estamos longe de poder afirmar que o pintor francês, que nasceu em Paris em 1826 e faleceu dois anos antes do findar do século XIX, tenha tratado toda a complexa tessitura do mito de Helena. É certo que começou, à semelhança dos mestres, por abordar temas tradicionais, como Le Jugement de Pâris, que foi inspirado por uma gravura de Marc-Antoine Raimondi realizada a partir de Rafael. Por volta de 1850, quando tinha 24 anos, desenhou um Enlèvement d'Hélène e regressou a esse tema quatro anos mais tarde ${ }^{(10)}$. No entanto, ao longo da sua produtiva carreira Gustave Moreau foi especialmente seduzido pela imagem da rainha de Esparta sobre as muralhas de Tróia, apresentada no canto III da llíada, pela imagem de uma beleza divina que é, ao mesmo tempo, admirada e temida pelos anciãos sentados junto das Portas Ceias (vv. 154-160):

Quando viram Helena avançar sobre o adarve, murmuraram entre si estas palavras aladas:

"Que os Troianos e os Aqueus de belas cnémides há tanto tempo sofram tanto por uma mulher assim, ninguém pode censurar.

Se olharmos para ela, infunde temor sua parecença com as deusas imortais! Mas, apesar da sua beleza, que embarque nos navios, que não a deixem aqui para castigo nosso e dos nossos filhos.»(11)

Helena é, de resto, apenas uma das muitas figuras femininas que iluminam o repertório de um pintor que ocupou um lugar único no panorama artístico da segunda metade do século XIX, para vir a ser considerado, no fim da vida, um precursor do movimento simbolista ${ }^{(12)}$, e que teve, entre os seus mais distintos discípulos, Albert Marquet, Henri Matisse e Georges Rouault.

Uma breve visita ao Museu Nacional Gustave Moreau, projectado pelo próprio e inaugurado a 14 de Janeiro de 1903, confirma a importância da mitologia greco-romana, dos temas bíblicos e da história antiga na sua obra ${ }^{(13)}$. $\mathrm{Na}$ construção deste universo, profundamente inspirado desde a mais terna juventude pela leitura dos Poemas Homéricos, de Hesíodo, das Metamorfoses de Ovídio, da Bíblia, de manuais de mitologia egípcia, grega, romana e celta, foi determinante a influência do pai. Arquitecto da cidade de Paris e grande admirador da Antiguidade, Louis Moreau incentivou o filho a concluir a formação em estudos clássicos antes de se dedicar por inteiro aos artísticos, mas não deixou de o apoiar quando decide estudar em Itália. Esta 
segunda viagem àquele país, realizada entre Outubro de 1857 e Setembro de 1859, teria um significado especial para o pintor, que nela depositou a esperança de completar a educação artística, como ele próprio afirmou: "Je vivrais là du peu que je possède parfaitement indépendant, sans inquiétude et travaillant comme un gamin à apprendre tout ce que j'ignore; après cela j'aurai l'esprit en repos, et la conscience plus calme.»(14).

À semelhança dos grandes mestres do passado, que estudou com fervor enquanto permaneceu em Itália, no universo greco-romano de Gustave Moreau ocupam lugar de relevo temas da llíada (e.g. Aquiles e Briseida, Helena, os amores de Zeus) e da Odisseia (e.g. Polifemo, Circe, As Sereias, os Pretendentes), bem como a saga dos Argonautas, os trabalhos de Héracles, o mito de Orfeu, Teseu, Prometeu e Édipo, mas também episódios célebres da história antiga, como o triunfo de Alexandre sobre o rei da Índia. Citando as palavras de Geneviève Lacambre, "ll est à la recherche, non pas de sujets nouveaux, mais d'une nouvelle manière de les traiter.»(15). Destaque-se ainda a série de obras que dedicou ao tema da inspiração poética, aos seus cultores mais antigos (Hesíodo, Tirteu e Safo) e aos seus patronos: Apolo e as Musas ${ }^{(16)}$.

Um dos momentos mais altos da carreira do artista foi a última participação no Salão de Paris, em 1880, no qual apresentou as obras Galatée e Hélène. A primeira retratava a Nereide insensivel à paixão do ciclope Polifemo, retomando o tema eterno do amor entre a bela e o monstro ${ }^{(17)}$. Desde 0 início do século XX que se desconhece o paradeiro da tela Hélène, da qual podemos formar uma pequena ideia através das impressões que causou nos visitantes da exposição e de reproduções ou variantes. Segundo documentos da época, o quadro media $200 \times 150 \mathrm{~cm}$ e retratava a rainha de Esparta numa atitude de impassível indiferença perante as vítimas da guerra(18). Sobre essa obra, o escritor e crítico de arte Joris-Karl Huysmans teceu o seguinte comentário:

"L'une représente Hélène, debout, droite, se découpant sur un terrible horizon éclaboussé de phosphore et rayé de sang, vêtue d'une robe incrustée de pierreries comme une châsse; tenant à la main, de même que la Dame de Pique des jeux de cartes, une grande fleur; marchant les yeux larges ouverts, fixe, dans une pose cataleptique. À ses pieds gisent des amas des cadavres percés de flèches, et, de son auguste beauté blonde, elle domine le carnage, majestueuse et superbe comme la Salammbô apparaissant aux mercenaires, semblable à une divinité malfaisante qui empoisonne, sans même qu'elle en ait conscience, tout ce qui l'approche ou tout ce qu'elle regarde et touche.»(19). 
Numa aguarela com o mesmo título e que terá sido pintada no mesmo ano(20), a figura estática de Helena, tal uma Cariátide do Erectéion de Atenas, surpreende-nos com o seu olhar distante, o longo cabelo louro, o colorido das vestes, irradiando uma luminosidade que contrasta terrivelmente com as figuras sombrias que jazem a seus pés. Parece claro que o pintor retratou aqui a mulher fatal que conduz à perdição, como as personagens bíblicas de Dalila e Salomé. À semelhança do poema homérico, o traço de Gustave Moreau põe em evidência a beleza de Helena e o sofrimento que essa beleza causou nos Aqueus e nos Troianos.

A mulher que amedronta com a expressão provocadora da sua sensualidade é um dos temas privilegiados da estética simbolista. É esse misto de sedução e perigo que surpreendemos em Oedipe et le Sphin $x^{(21)}$, a tela que havia sido a revelação do Salão de Paris de 1864. O pintor tinha então 38 anos. Até à última participação nesse importante certame artístico, nunca deixou de expor obras centradas em temas clássicos, tratados geralmente com ousadia e singularidade.

A Hélène levada ao Salão de 1880 impressionou os visitantes e inspirou os jovens escritores da época, como Théodore de Banville, Henri de Régnier e Albert Samain, entre outros (cf. Mathieu 1985: 7779, Cooke 2002). O poema mais conhecido é, talvez, "Sur l'Hélène de Gustave Moreau», de Jules Laforge, célebre pela ironia que se revela principalmente no último verso(22):

Frêle sous ses bijoux, à pas lents, et sans voir

Tous ces beaux héros morts, dont pleurent les fiancées,

Devant l'horizon vaste ainsi que ses pensées, Hélène vient songer dans la douceur du soir.

"Qui donc es-tu, Toi qui sèmes le désespoir?", Lui râlent les mourants fauchés là par brassées,

Et la fleur qui se fane à ses lèvres glacées

Lui dit: "Qui donc es-tu?" de sa voix d'encensoir.

Hélène cependant parcourt d'un regard morne La mer, et les cités, et les plaines sans borne, Et prie: "Oh! c'est assez, Nature! reprends-moi!

Entends! Quel long sanglot vers nos Lois éternelles!» - Puis, comme elle frissonne en ses noires dentelles, Lente, elle redescend, craignant de "prendre froid". 
Apesar das manifestações de admiração(23), Gustave Moreau retirou-se das exposições oficiais, decepcionado com a forma como a sua obra era recebida, como um caso à parte e não verdadeira pintura histórica. Continuou a trabalhar com devoção e entrega, recebia os amigos no seu ateliê, mas raramente mostrava as obras em curso e só voltou a expor em ocasiões excepcionais. Nos últimos anos de vida, dedicou-se aos seus discípulos da École des Beaux Arts de Paris e, como já referimos, é inegável a influência sobre a nova geração de artistas do princípio do século XX.

Gustave Moreau tinha por hábito trabalhar nas suas telas durante vários anos e regressava com frequência aos mesmos temas, criando variantes. O tratamento da figura de Helena permite também testemunhar a maturação da técnica artística, bem como a evolução do seu pensamento, embora as diferenças entre as diversas obras não sejam, à primeira vista, muito notórias. Por volta do mesmo ano de 1880 , compôs também Hélène à la porte Scée. Ainda que tenha feito um desenho preparatório bastante preciso ${ }^{(24)}$, a versão definitiva distingue-se por um estilo quase abstracto e pelo contraste violento entre 0 cinzento do céu e do rosto de Helena, o branco das muralhas troianas e, em primeiro plano, os tons avermelhados das vítimas e das vestes da heroína ${ }^{(25)}$. Numa outra obra que não podemos datar, o contraste cromático estabelece-se entre a figura fantasmagórica de Helena e o cenário em que ela surge, que nos faz pensar na cidade de Tróia em ruínas ${ }^{(26)}$. Num desenho realizado em 1881 (Hélène) ${ }^{(27)}$ e numa aguarela pintada por volta de 1885 (Hélène sur les murs de Troie)(28), a atitude das personagens é semelhante à das versões anteriores, mas o pintor desenhou com maior precisão as vítimas, os ornamentos das vestes de Helena, a flor que segura na mão, apenas esboçada nas versões (preservadas) mais antigas. No olhar distante da rainha de Esparta notamos agora um misto de amargura e resignação, que não pode deixar de lembrar a personagem complexa da llíada, que a todo o momento se censura pelos sofrimentos causados a Argivos e Troianos ${ }^{(29)}$.

Apesar das pequenas diferenças que ao longo de anos foi introduzindo nas suas obras, é evidente que o pintor se manteve fiel a uma ideia: Helena é retratada de pé, por vezes de perfil, com um olhar visivelmente distante num rosto de uma beleza singela; na indumentária vistosa sobressaem as cores brilhantes e as jóias; a sua figura resplandecente destaca-se de um cenário sombrio, as muralhas ou as ruínas de Tróia, surgindo em primeiro plano os cadáveres de 
soldados jovens ou de habitantes da cidade, amontoados ou encostados uns aos outros, parecendo, em algumas telas, que estão apenas a descansar. A semelhança destes corpos com a imagem convencional de São Sebastião não parece ser coincidência.

Esta evolução atinge o auge por volta de $1887 \mathrm{com}$ o tema da apoteose de Helena, inspirado pela leitura do Segundo Fausto de Johann Wolfgang von Goethe ${ }^{(30)}$. O conjunto de obras que Moreau compôs sob o título Hélène glorifiée manteve alguns tópicos dos quadros mais antigos: a mais bela mulher da Grécia continua a ocupar o centro da tela, num plano elevado ao das restantes personagens, com uma flor nas mãos e sem cruzar os olhos com os que a rodeiam. No entanto, nas três versões que conhecemos, Helena surge agora em ascensão, nua, no centro de um grupo de figuras masculinas, numa postura de quase adormecimento, com a mãe esquerda atrás da cabeça e a direita, que segura a flor, próxima do rosto. Estão ausentes os cadáveres das obras que antes analisámos. Na grande tela exposta no Museu Nacional Gustave Moreau, iniciada por volta de 1893, mas que não chegou a ser acabada, as personagens masculinas olham-na com reverência e veneração. No lado inferior esquerdo, foi retratado um Génie ou Eros com os traços típicos: alado e deitado sobre uma espécie de escudo. A primeira figura do lado direito, com uma coroa na cabeça, representa provavelmente um rei. As outras duas são identificadas nos desenhos preparatórios como soldados ${ }^{(31)}$. Uma aguarela pintada alguns anos mais tarde, na qual diversificou a paleta de cores, parece levar a nova imagem de Helena a um idealismo extremo, que se reflecte na atitude das personagens que a rodeiam: Eros esconde o rosto e o olhar das outras figuras masculinas (o rei, o soldado e o poeta), está mais próximo do temor do que da admiração dos devotos ${ }^{(32)}$.

A mulher fatal que "semeia o desespero", como escreveu Jules Laforge, insensível às vítimas que jazem a seus pés, revela-se agora em glória, contemplada por seres masculinos em estado de êxtase. A diferença mais significativa, porém, é o predomínio de elementos iconográficos cristãos, designadamente a influência dos ícones bizanti$\operatorname{nos}^{(33)}$, como a imagem da ascensão ou a presença de uma auréola à volta da cabeça numa das variantes ${ }^{(34)}$. Em nosso entender, esta associação da figura extraordinária de Helena a uma dimensão sagrada está mais de acordo com as crenças antigas e os cultos que lhe eram prestados em algumas regiões da Hélade, em especial no Peloponeso, e no Egipto ${ }^{(35)}$, do que com a ideia, já expressa na llíada (e.g. 
vv. 3. $164-165,6.349,357-358)$, de que a rainha de Esparta fora também uma vítima dos deuses e do destino, como pensam alguns estudiosos $^{(36)}$. Representada como símbolo da beleza perfeita, Helena assume os traços primordiais da divindade. Talvez por essa razão, o pintor continuou a retratá-la com a flor na mão, símbolo de realeza e principalmente de espiritualidade ${ }^{(37)}$.

Pintor-poeta ou mestre de sonhos, Gustave Moreau recriou nas suas obras a história de Dalila, Salomé, Helena, Cleópatra, Messalina, e evocou outros seres, como as sereias e as fadas da mitologia celta, que têm em comum o poder de sedução e de encantar os homens. No pensamento do artista, que sempre se considerou um "peintre d'histoire", embora preferisse a designação de "grand art", a obra de arte não devia ser uma ilustração pura dos textos literários ou religiosos, mas somente a sua evocação, abrindo o caminho ao mistério, à imaginação, à metáfora, à sedução dos sentidos. Marie-Cécile Forest, directora da casa-museu do pintor, fala de "nécessité impérieuse d'inventer" e cita as palavras de Roger Marx extraídas da Gazette des Beaux-Arts de 1895: "Au rebours, M. Gustave Moreau entend ressusciter les vieux mythes oubliés de l'Orient, de la Grèce, et il les pare d'une jeunesse éternelle par une compréhension renouvelée, par l'imprévu de la mise en scène et du métier.»(38).

O pintor torna-se assim, ele próprio, num poeta ou, como dirá várias vezes, num "assembleur de rêves", que deve poder conseguir dar ao mito toda a intensidade que ele possa ter, sem o tornar escravo das convenções do estilo ou da época ${ }^{(39)}$.

\section{Notas}

() Este estudo foi elaborado a partir de uma pesquisa efectuada em Março de 2006 no Museu Nacional Gustave Moreau, durante um estágio em França apoiado pelo Serviço de Educação e Bolsas da Fundação Calouste Gulbenkian. O presente texto, embora mais extenso, é publicado sem as imagens que apresentámos na comunicaçăo ao Congresso Internacional "O mito de Helena: de Tróia aos nossos dias", organizado pelo Centro de Estudos Clássicos e Humanísticos da Universidade de Coimbra ( 3 e 4 de Abril de 2006). Quase todas as obras de Gustave Moreau podem ser visualizadas na Internet, em especial através da base Joconde, que reúne as colecções dos museus de França (http:// www.culture.gouv.fr/documentation/joconde/fr/pres.htm).

(1) Cf. Cypria, fr. 10 West; Apollod. 3. 10. 7, Paus. 3. 16. 1, Hyg. Fab. 77. Nos Poemas Homéricos, Helena é filha de Zeus (e.g. II. 3. 418, Od. 4. 184) e depreende-se que a mãe seja Leda. Na lliada, a princesa de Esparta pensa nos irmãos Dioscuros e na mãe, mas não menciona o nome (3. 237-238). Na Odisseia, Leda é esposa de Tíndaro e mãe dos 
Dioscuros (11. 298-300). Para uma análise da tradição literária e iconográfica sobre o tema, vide GHALI-KAHIL 1988: 498, 562.

(2) LIMC, s.v. Helene n. ${ }^{\circ}$ 5, c. 380-370 a. C. Bari, Museo Archeologico (3899).

(3) LIMC, s.v. Helene n.ำ 9, c. 340 a. C. Nápoles, Museo Nazionale (147950).

(4) No canto III da lliada (vv. 143-144), uma das criadas de Helena é a mãe de Teseu, Etra. Aristarco considerou o passo uma interpolação, mas o poeta alude com frequência a mitos que não desenvolve. A lenda do rapto pode ter sido tratada nos Cantos Cíprios, de acordo com um escoliasta (schol. D ad II. 3. 242 = Cypria, fr. 12 West), e também por Álcman, segundo Pausânias (1. 41. 4 = Alcm. fr. 21 Page). Cf. Hdt. 9. 73, D.S. 4. 63, Str. 9. 1. 17; Apollod. 3. 10. 7, Epit. 1. 23; Plu. Thes. 31 sqq.; Paus. 1. 17. 6, 2. 22. 7, 2. 32. 7; Hyg. Fab. 79.

(5) LIMC, s.v. Helene n. ${ }^{\circ} 30$, c. 520-510 a. C. Londres, British Museum (B 310).

(6) LIMC, s.v. Helene n.ำ 62, c. 480 a. C. Berlim, Staatliche Museen (F 2205).

(7) LIMC, s.v. Helene n. ${ }^{\circ} 310$, c. $515-500$ a. C. Odessa (Ucrânia), Museum of Western and Eastern Art (0.577).

(8) LIMC, s.v. Helene n. ${ }^{2} 248$, c. 470 a. C. Londres, British Museum (E 161). Sobre a identificação da figura feminina com Afrodite, cf. GHALI-KAHIL 1988: 559, WOODFORD 2003: 86-87, MANGOLD 2005: 78.

(9) Para se ter uma pequena ideia da importância do mito de Helena nas artes, veja-se a compilação de REID 1993, s.v. Helen of Troy, com 156 entradas, o que faz deste artigo um dos maiores do dicionário. Vide ainda, para a pintura, DOMMERMUTH-GUDRICH 2004: 124-129.

(10) Enlèvement d'Hélène, 1854. Óleo sobre madeira, $40,5 \times 48 \mathrm{~cm}$. Paris, Collection Brame et Lorenceau. Vide MATHIEU 1998: 35.

(11) Citamos a tradução de M. H. ROCHA PEREIRA, Hélade. Antologia da Cultura Grega, Lisboa, Guimarães Editores, 2009 (10 ed.).

(12) A publicação do Manifeste symboliste de Jean Moréas, no Figaro de 18 de Setembro de 1886, assinala a fundação do movimento, na origem literário, que proclamava a renúncia ao naturalismo e o horror à obra de Émile Zola. As principais referências eram Baudelaire, Verlaine e, em especial, Stéphane Mallarmé. A monografia sobre o Simbolismo das edições Benedikt Taschen, da autoria de Michael Gibson, publicada em 2006, analisa nos capítulos introdutórios o papel influente de Gustave Moreau.

(13) O Museu Nacional Gustave Moreau, antiga residência e ateliê do artista, permanece como ele desejou. Em 1987 acolhia cerca de 850 pinturas, 350 aguarelas e perto de 5000 desenhos (J. PALADILHE, Petit guide des grands musées, n.ำ52: Musée National Gustave Moreau, Paris, Éditions RMN, 1987, p. 4), mas a obra de Moreau está dispersa por museus e colecções particulares do mundo inteiro. Vide http://www.musee-moreau.fr/ e http://www.artcyclopedia.com/artists/moreau_gustave.html (acedidos em 20/07/2010).

(14) Citado em MATHIEU 1998: 41. Sobre a importância das viagens a Itália na formação artistica de Moreau, cf. G. LACAMBRE, in Lacambre et Leyge 2001: 35-40.

(15) Ibidem, p. 48. A importância dos temas greco-romanos na obra de Gustave Moreau tem sido discutida por diversos especialistas, designadamente Peter Cooke, Mireille DottinOrsini, Marie-Cécile Forest, Geneviève Lacambre, Pierre-Louis Mathieu, Maria Luisa Frongia e Evangelista Stead. 
(16) Sobre este assunto, vide o nosso estudo (2009), "A herança clássica na pintura de Gustave Moreau. O tema de Safo", Boletim de Estudos Clássicos 51: 111-116.

(17) Galatée, 1880. Óleo sobre madeira, $85 \times 67 \mathrm{~cm}$. Paris, Musée d'Orsay. Vide MATHIEU 1994: 143, 1998: 119; COOKE 2002: 38.

(18) Cf. MATHIEU 1985: 77, COOKE 2002: 39. O quadro perdeu-se em 1913, quando se dispersou a colecção Jules Beer, à qual pertencia. Cf. DOTTIN-ORSINI 2000: 2-3, MATHIEU 1994: 146.

(19) JORIS-KARL HUYSMANS (1883), "Le Salon officiel de 1880", in L'Art Moderne. Paris:

G. Charpentier, 154, citado também em MATHIEU 1994: 146.

(20) Hélène, c. 1880. Aguarela, $33 \times 24,5 \mathrm{~cm}$. Paris, Musée National Gustave Moreau (Cat. 483). Vide LACAMBRE et LEYGE 2001: 15; P. DEMONT (2004), The lliad and the Odyssey. Troy. Oxford: Hachette Illustrated UK: 31.

(21) Oedipe et le Sphinx, 1864. Óleo sobre tela, 206,4 x 104,7 cm. Nova lorque, Metropolitan Museum of Art (21.134.1). Vide MATHIEU 1994: 72, 1998: 68-69; http:// www.metmuseum.org/toah/works-of-art/21.134.1 (acedido em 21/07/2010).

(22) O soneto de Jules Laforge (1860-1887) foi publicado pela primeira vez em Poésies complètes, vol. I, Paris, Gallimard, 1970. Para uma análise, vide DOTTIN-ORSINI 2000.

(23) A admiração pelo pintor inspirou ao escritor Joris-Karl Huysmans um dos capítulos do romance $\dot{A}$ Rebours (o cap. V), publicado em 1884, cujo protagonista, o duque des Esseintes, decora o quarto com obras de Gustave Moreau.

(24) Hélène à la porte Scée, c. 1880. Mina de chumbo sobre papel, 8,5 × 12,9 cm. Paris, Musée National Gustave Moreau (Des. 131). Vide MATHIEU 1994: 144.

(25) Hélène à la porte Scée, c. 1880. Óleo sobre tela, $72 \times 100 \mathrm{~cm}$. Paris, Musée National Gustave Moreau (Cat. 42). Vide MATHIEU 1994: 144; P. DEMONT, op. cit., pp. 32-33.

(26) Hélène sur les remparts de Troie. Óleo sobre tela, $100 \times 61 \mathrm{~cm}$. Paris, Musée National Gustave Moreau (Cat. 58). Vide DOMMERMUTH-GUDRICH 2004: 128.

(27) Hélène, c. 1881. Pluma e aguada de tinta escura sobre traços de mina de chumbo, 29 x $16 \mathrm{~cm}$. Genebra, Galerie Jan Krugier. Vide MATHIEU 1994: 230.

(28) Hélène sur les murs de Troie, c. 1885. Aguarela, $36,7 \times 17 \mathrm{~cm}$. Paris, Musée du Louvre, Département des Arts graphiques (RF 32135, recto). Vide MATHIEU 1994: 145, 1998: 128.

(29) Cf. lliada 3. 171-180, 6. 344-358, 24. 761-775.

(30) O poeta alemão retoma o mito de Helena no momento da conquista de Tróia. Prestes a ser condenada à morte, a rainha de Esparta é salva in extremis graças a uma bruma misteriosa. Segue-se a sua apoteose. O Acto III, escrito entre 1825-1827, foi primeiramente publicado sob o título "Helena. Klassisch romantische Phantasmagorie" (1827) e incorporado depois em Fausto, publicado postumamente (HEIDELBERG, 1832). Cf. MATHIEU 1985: 79-80, 1994: 219, 231; F. LEYGE in Lacambre et Leyge 2001: 68.

(31) Hélène glorifiée, c. 1893 . Óleo sobre tela, $230 \times 120 \mathrm{~cm}$. Paris, Musée National Gustave Moreau (Cat. 217).

(32) Hélène glorifiée, c. 1896-1897. Aguarela com retoques de guache, $30 \times 23 \mathrm{~cm}$. Tóquio, Colecção Lecien Corp. Vide MATHIEU 1998: 171. No artigo publicado em 1985 (p. 80 n. 12), P.-L. Mathieu notou que a composição de Moreau retoma as figuras (Eros/putto, rei, 
soldado e poeta) que aparecem no óleo sobre tela Hélène, realizado em 1892 por Henri Fantin-Latour, hoje preservado no Museu do Petit Palais de Paris.

(33) A base de dados Joconde regista um Étude d'Hélène en costume byzantin (Paris, Musée National Gustave Moreau, Des. 5608).

(34) Hélène glorifiée, c. 1887. Aguarela sobre papel, $19 \times 12 \mathrm{~cm}$. Paris, Musée National Gustave Moreau (Cat. 488).

(35) Chegaram-nos alguns testemunhos literários e arqueológicos sobre a natureza destes cultos. O mais antigo pode ser a informação de Hecateu de Mileto ( $F G r H 1 F$ 309) sobre a existência de um Heleneion ou templo em honra de Helena no Egipto (cf. Hdt. 2. 112). $\mathrm{Na}$ região da Lacónia, Helena e Menelau eram venerados como heróis (cf. Hdt. 3. 61. 3; Paus. 3. 15. 3, 3. 19. 9 ) e as escavações arqueológicas realizadas no Menelaion de Terapne, iniciadas na primeira metade do século XIX e retomadas na década de 70 do século XX, permitiram recuperar inscrições do século VII a. C. de ofertas votivas a Helena. No entanto, em Esparta (Theocr. 18. 38-40) e em Rodes (Paus. 3. 19. 10), pelo menos, também era venerada como deusa das árvores. Notícias transmitidas por Heródoto (6. 61) e Pausânias (3. 7. 7) atestam ainda que em Esparta se acreditava no seu poder sobre a beleza das mulheres. Para uma análise deste tema, vide B. HUGUES (2008), Helena de Tróia. Deusa, princesa, prostituta. Trad. port. Maria José Santos. Lisboa: Alêtheia Editores.

(36) Cf. F. LEYGE, in Lacambre et Leyge: 68.

(37) A flor, muitas vezes o lírio, surge em especial nas telas das figuras femininas mais célebres de Moreau (e.g. Salomé dansant devant Hérode, 1876; Rêve d'Orient, 1881; Les Licornes, c. 1885-1890; Cléopâtre, c. 1887). Por volta de 1890, o artista tratou o tema numa das suas obras mais importantes: Fleur mystique, $253 \times 128 \mathrm{~cm}$, Paris, Musée Nationai Gustave Moreau. Vide MATHIEU 1998: 150.

(38) MARIE-CÉCILE FOREST, "Une figure obsédante", in TDC-Textes et documents pour la classe, n. 891 ( "Le mythe d'Orphée", edição de 1/03/2005). Consultado em http:// www.sceren.fr/revueTDC/891 72868.htm (acedido em 2/04/2006).

(39) Cf. MATHIEU 1994: 146, 151; G. LACAMBRE, in Lacambre et Leyge 2001: 12, 41-57.

\section{Bibliografia}

CHALEIL, F. ed. (1998), Gustave Moreau par ses contemporains. Paris: Les Éditions de Paris.

COOKE, P. (2002), "Critique d'art et transposition d'art: autour de Galatée et d'Hélène de Gustave Moreau (Salon de 1880)", Romantisme: revue du dix-neuvième siècle 118: 37-53.

DOMMERMUTH-GUDRICH, G. (2004), Mythes. Les plus célèbres mythes de l'Antiquité. Trad. fr. C. Monnatte. Paris: Éditions de La Martinière, 124-129.

DOTTIN-ORSINI, M. (2000), "Un mythe épisodique: Hélène de Troie chez Jules Laforgue", Vortex, Revue de L'association Jules Laforgue, n.⒉ 2. Disponivel em http:// www.orsini.net/laforgue/vortex2/dottin2.htm (acedido em 19/07/2010).

GHALI KAHIL, L. B. (1955), Les enlèvements et le retour d'Hélène dans les textes et les documents figurés. Paris: E. de Boccard.

GHALI KAHIL, L. B. (1988), Lexicon Iconographicum Mythologiae Classicae (LIMC). Vol. IV. Zürich-München: Artemis Verlag, s.v. Helene. 
LACAMBRE, G. (1999), Gustave Moreau. Magic and Symbols. New York: Harry N. Abrams, Inc.

LACAMBRE, G. et LEYGE, F. (2001), Gustave Moreau et l'Antique. Édition de la Ville de Millau.

MANGOLD, M. (2005), Guide d'imagerie antique. La chute de Troie sur les vases attiques. Trad. fr. A. De Minicis. Gollion: Infolio.

MATHIEU, P.-L. (1985, Setembro), "Gustave Moreau et le mythe d'Hélène", Gazette des Beaux-Arts, 76-80.

MATHIEU, P.-L. (1994), Gustave Moreau. Paris: Flammarion.

MATHIEU, P.-L. (1998), Gustave Moreau, L'assembleur de rêves. Paris: ACR Édition.

REID, Jane D. (1993), The Oxford Guide to Classical Mythology in the Arts, 1300-1990s. Vol. I. New York-London: Oxford University Press, s.v. Helen of Troy.

WEST, M. L. (2003), Greek Epic Fragments from the Seventh to the Fifth Centuries BC. Cambridge, Mass.: Harvard University Press.

WOODFORD, S. (2003), Images of Myths in Classical Antiquity. Cambridge: University Press. 